\title{
Overexpression of Type I Adenylyl Cyclase in the Forebrain Impairs Spatial Memory in Aged But Not Young Mice
}

\author{
Michael G. Garelick, Guy C. K. Chan, Derek P. DiRocco, and Daniel R. Storm \\ Department of Pharmacology, University of Washington, Seattle, Washington 98195
}

\begin{abstract}
Hippocampus-dependent memory requires a cAMP signal that is generated by $\mathrm{Ca}^{2+}$-stimulated adenylyl cyclases (AC1, AC8). Young transgenic mice overexpressing $\mathrm{ACl}$ in the forebrain $\left(\mathrm{ACl}^{+}\right.$mice) have enhanced hippocampal long-term potentiation, superior memory for novel object recognition and more persistent remote contextual memory. To determine whether increasing AC1 expression improves memory when older mice are trained, we analyzed fear, recognition, and spatial memory in mice aged to 25 months. Here we report that young adult $\mathrm{ACl}^{+}$mice have enhanced social recognition memory, and normal fear and spatial memory. Surprisingly, aged $\mathrm{ACl}^{+}$mice had poorer spatial memory than age-matched wild-type littermates. These data suggest that the decrease in $\mathrm{Ca}^{2+}$-stimulated adenylyl cyclase activity during aging of wild-type mice may be an adaptive mechanism required to maintain spatial memory function.
\end{abstract}

\section{Introduction}

Research with rodent models of learning and memory has identified several signaling events critical for the formation of long-term memory, including generation of $\mathrm{Ca}^{2+}$ signals through NMDA receptors, activation of ERK (extracellular signal-regulated kinase)/MAPK (mitogen-activated protein kinase), and stimulation of calmodulinstimulated adenylyl cyclases (Wu et al., 1995; Wong et al., 1999). $\mathrm{Ca}^{2+}$-stimulated cAMP production in hippocampal neurons is a critical step for the integration of these pathways during learning and for the generation of long-term memory (Sindreu et al., 2007). AC1 knock-out mice have impaired spatial memory and long-term potentiation (LTP) (Wu et al., 1995) whereas mice lacking both AC1 and AC8 [double knock-out (DKO) mice] have no long-lasting LTP as well as deficits in passive avoidance, contextual fear, and recognition memory (Wong et al., 1999; Wang et al., 2004). Because AC1 is a neurospecific $\mathrm{Ca}^{2+}$-stimulated adenylyl cyclase (Xia et al., 1993), it is an obvious drug target site to selectively increase cAMP signaling in the CNS to improve memory.

Normal aging is often accompanied by impaired memory (Toescu, 2005; Kelly et al., 2006; Thibault et al., 2007). Possible mechanisms for age-related memory impairment include attenuated cAMP/CREB signaling. Aged rodents show lower levels of cAMP (Tombaugh et al., 2005) and phosphorylated CREB in the hippocampus than younger rodents after training (Mouravlev et al., 2006). Pharmacological inhibition of phosphodiesterases or virally mediated overexpression of hippocampal CREB both improve hippocampus-dependent memory in aged rodents (Barad et al., 1998; Bach et al., 1999; Mouravlev et al., 2006).

\footnotetext{
Received Feb. 2, 2009; revised June 29, 2009; accepted July 21, 2009.

This project was funded by National Institutes of Health Grants MH073601 and R01 NS0498. M.G.G. was funded in part by National Institute on Aging Grant T32 AG 00057. We thank R. D. Palmiter for use of the Barnes maze apparatus, and members of the Storm laboratory for critical reading and suggestions for this manuscript. Correspondence should be addressed to Daniel R. Storm at the above address. E-mail: dstorm@u.washington.edu. DOI:10.1523/JNEUROSCI.0553-09.2009

Copyright $\odot 2009$ Society for Neuroscience $\quad$ 0270-6474/09/2910835-08\$15.00/0
}

Since $\mathrm{Ca}^{2+}$-stimulated adenylyl cyclases are required for memory function, we reasoned that overexpression of AC1 might benefit memory. Therefore, $\mathrm{ACl}^{+}$mice were generated using an $\alpha$-CaM kinase II promoter to drive expression in the forebrain. These mice show enhanced late-phase Schaffer collateral/CA1 LTP and increased ERK/MAPK and CREB signaling (Wang et al., 2004). Furthermore, young adults have superior memory for novel objects and show retention of contextual fear memory over longer periods of time than wild-type mice (Shan et al., 2008). Since attenuated CAMP and CREB signaling have been implicated in age-related memory impairments, we hypothesized that the memory benefits observed in young adult $\mathrm{AC}{ }^{+}$mice would extend into advanced age.

To examine the role of $\mathrm{ACl}$ and memory function in advanced age, we examined $\mathrm{Ca}^{2+}$-stimulated cyclase activity in young and aged wild-type adult mouse brain tissue. We then examined aged $\mathrm{ACl}^{+}$mice with tests in which impaired memory performance by aged rodents had been reported. Aged $\mathrm{AC}^{+}$ mice were tested for performance on fear, recognition, and spatial memory tasks, tasks that require intact hippocampus and $\mathrm{Ca}^{2+}$-stimulated adenylyl cyclases for normal memory performance. We found that whereas $\mathrm{Ca}^{2+}$-stimulated adenylyl cyclase activity is decreased in the aged hippocampus, there was no benefit of AC1 overexpression in fear or recognition memory. Furthermore, we report the surprising observation that $\mathrm{ACl}$ overexpression impaired spatial memory in aged mice.

\section{Materials and Methods}

Animals. Experiments were in accordance with and approved by the animal care committee's guidelines at the University of Washington. $\mathrm{AC}^{+}$mice were homozygous for the $\mathrm{ACl}$ transgene expressed by the $\alpha$-CaMKII promoter and were generated as previously described (Wang et al., 2004). $\mathrm{ACl}^{+}$mice were mated with C57BL/6 mice (Taconic) and $\mathrm{AC}^{+}{ }^{+}$offspring were group housed with wild-type littermates. DKO mice were generated as previously described (Wong et al., 1999; Wang et al., 2004). Wild-type C57BL/6 mice (Taconic) were used as controls for Barnes maze experiments with DKO mice. $\mathrm{ACl}^{+}$and $\mathrm{DKO}$ lines were bred into a C57BL/6 background for at least nine generations. Male mice 
were used for all experiments. In all behavioral experiments, mice aged between 3 and 4 months were defined as young, and mice aged between 25 and 27 months were defined as aged. Separate groups of mice were used for behavioral tests of young and aged mice.

Barnes maze. The fiberglass Barnes maze apparatus used was $140 \mathrm{~cm}$ long in diameter and $140 \mathrm{~cm}$ high. There were 28 holes equally spaced along the edge of the circular platform. A shaded goal box was placed under one of the holes. In addition to the behavior room's florescent lighting, three $60 \mathrm{~W}$ lamps were used to increase lighting on the maze surface. Display boards containing shapes were placed 2 feet from the edge of the maze on opposite sides.

We used a paradigm with multiple training sessions per day modified from Dai et al. (2007). The Barnes maze test consisted of 6 training sessions spaced $24 \mathrm{~h}$ apart followed by a probe test $24 \mathrm{~h}$ after the last training session. During the first session, each mouse was placed into the goal box for $1 \mathrm{~min}$. The mouse was then placed in the center of the maze facing a random quadrant and allowed to explore the maze. If the mouse did not enter the goal box within $3 \mathrm{~min}$, the mouse was gently guided to the goal box by the experimenter. Mice remained in the goal box for $1 \mathrm{~min}$. During this time, the surface of the Barnes maze was washed with Clidox solution to neutralize olfactory cues. Mice were submitted to four trials separated by $1 \mathrm{~min}$ in the goal box during each session. Subsequent sessions were run the same way, with the exception that the mouse was not placed in the goal box before the start of the first trial. For the probe trial, the goal box was removed from the maze. The mouse was allowed to explore for $2 \mathrm{~min}$.

Passive avoidance. Passive avoidance learning experiments were conducted in a chamber consisting of a glass enclosure and an electrified floor. The chamber was divided into two sections by a metal partition with a sliding trap door. One side of the box was shielded from light and the other was exposed to light. During training, mice received a foot shock when they entered the shaded side $(0.7 \mathrm{~mA}, 2 \mathrm{~s})$. Mice remained in the shaded side for $1 \mathrm{~min}$ after the shock. During testing the mice were placed into the illuminated side of the box and allowed to roam freely to the darkened half. Escape latencies, defined as the time it took for mice to cross completely to the darkened half, were recorded.

Novel object recognition. Mice were tested as described by Wang et al. (2004). Briefly, mice were individually habituated to a novel cage for $4 \mathrm{~h}$ before training. Training consisted of placing two plastic blocks with different shapes into the cage. Investigation of the object was scored by the number of approaches to the object and the time spent exploring the object. Exploration was defined as approaching the object within 1 inch and facing the object, but did not include sitting or climbing on the object. During the 5 min training session, less than half of the mice aged 2 years explored the objects for $30 \mathrm{~s}$ or longer.

Social recognition. For the recognition test, male experimental mice were exposed to ovariectomized females to reduce the potential for fighting or aggressive behavior. Every $10 \mathrm{~min}$, the same female was placed in the cage as the experimental mouse for $1 \mathrm{~min}$ for a total of six times. At the end of training, mice were returned to their group-housed home cage. For testing sessions, the experimental mice were placed back into the experimental cages. The experimental mice were then exposed to a novel and familiar ovariectomized mouse, 10 min apart. Exploration time was scored as described by (Kogan et al., 2000). Preference index was scored as the ratio of time spent exploring the novel mouse over time spent exploring the familiar mouse.

Adenylyl cyclase assay. Hippocampi were dissected from aged and young mice and frozen on dry ice. Tissue was pooled into samples of three hippocampi from three different mice for each experimental group, and each pooled sample was assayed in triplicate. The average value from the triplicates was used for statistical analysis. Frozen brain tissue from the National Institute on Aging Tissue Bank was thawed and cortical, hippocampal, and cerebellar tissue were dissected and pooled in the same manner. Adenylyl cyclase activity in membrane preparations from wild-type and transgenic mice was determined as previously described (Eckel-Mahan et al., 2008). Protein concentrations of samples were determined with the BCA assay (Pierce) performed according to the manufacturer's instructions.
Western analysis. Mice were killed by cervical dislocation and hippocampi were quickly dissected and frozen with dry ice. Western analysis was performed as previously described (Sindreu et al., 2007). Primary antibodies included: rabbit anti-pCREB from Cell Signaling; mouse anti- $\beta$ III tubulin from Promega, rabbit anti-GFAP from Sigma, and mouse anti-actin from Millipore Bioscience Research Reagents. Alkaline phosphatase-conjugated secondary antibodies were from Sigma.

cAMP ELISA. cAMP ELISA analysis was performed as previously described (Wang et al., 2004).

Statistical analysis. Statistical analysis was performed on Prism software (version 4.0, GraphPad). Adenylyl cyclase assays on pooled tissue homogenates from the National Institute on Aging Tissue Bank were analyzed for age and treatment effects with two-way ANOVA with repeated measures matched across the treatment condition. Adenylyl cyclase assays of $\mathrm{AC}^{+}$and wild-type hippocampi were analyzed for genotype and treatment effects with two-way ANOVA with repeated measures matched across the treatment condition. Effects of genotype and age on social recognition, passive avoidance, and Barnes maze data were analyzed by two-way ANOVA with repeated measures matched across behavioral conditions. Post hoc comparisons were made with the Bonferroni post hoc test. Preference index for social recognition, ELISA, and Western blot data were analyzed with unpaired Student's $t$ tests.

\section{Results}

$\mathrm{Ca}^{2+}$-stimulated adenylyl cyclase activity decreases with age

$\mathrm{Ca}^{2+}$-stimulated adenylyl cyclase activity peaks in the juvenile brain and declines by adulthood (Villacres et al., 1995; Conti et al., 2007). Therefore, we sought to determine whether $\mathrm{Ca}^{2+}$ stimulated adenylyl cyclase activity continues to decrease through advanced aging. Whole brains harvested from C57BL/6 mice at 4, 12, and 24 months were obtained from the National Institute on Aging Tissue Bank. Membrane fractions from cortex, hippocampus, and cerebellum were assayed for adenylyl cyclase activity in the absence or presence of $5 \mu \mathrm{M}$ free $\mathrm{Ca}^{2+}$ (Fig. 1). This assay tests the adenylyl cyclase enzyme activity present in the fractionated membranes purified from the tissue sample, and thus tests the activity of all adenylyl cyclases present in the tissue, not specifically AC1. $\mathrm{Ca}^{2+}$-stimulated activity is not observed in this assay in tissue lacking AC1 and AC8 (Wong et al., 1999). All samples exhibited $\mathrm{Ca}^{2+}$-stimulated adenylyl cyclase activity $(p<0.01)$. In the hippocampus, $\mathrm{Ca}^{2+}$-stimulated adenylyl cyclase activity was $\sim 2$-fold lower at 12 and 24 months compared with the 4 month age group (Fig. 1A). In the cortex, no significant differences were observed in $\mathrm{Ca}^{2+}$-stimulated adenylyl cyclase activity at 12 and 24 months compared with 4 months (Fig. $1 B$ ). In the cerebellum, $\mathrm{Ca}^{2+}$-stimulated cyclase activity was lower at 12 and 24 months than at 4 months (Fig. 1C). These data indicate that $\mathrm{Ca}^{2+}$-stimulated adenylyl cyclase activity is decreased in the aged hippocampus and cerebellum.

\section{$\mathrm{AC}^{+}$mice show normal passive avoidance fear memory}

Since $\mathrm{Ca}^{2+}$-stimulated adenylyl cyclase activity is decreased in the aged hippocampus, and since $\mathrm{Ca}^{2+}$-stimulated adenylyl cyclases contribute to the formation of long-term memories (Wong et al., 1999b; Sindreu et al., 2007; Eckel-Mahan et al., 2008), we hypothesized that $\mathrm{ACl}$ overexpression might benefit hippocampusdependent memory in aged mice. Thus, we tested memory tasks that had been reported to be impaired in advanced age, involve the hippocampus, and in which $\mathrm{Ca}^{2+}$-stimulated adenylyl cyclases contribute to memory function. We reasoned that we would be most likely to detect memory enhancement by $\mathrm{ACl}^{+}$in aged mice with tasks that met these criteria. To demonstrate a role of $\mathrm{Ca}^{2+}$-stimulated adenylyl cyclases in a memory task, we tested DKO mice since DKO memory deficits are more severe than 
A Hippocampus

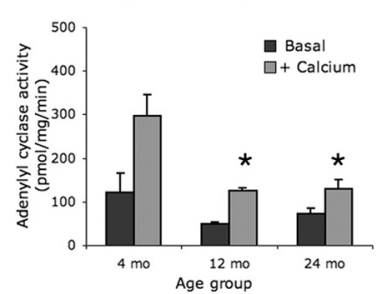

B Cortex

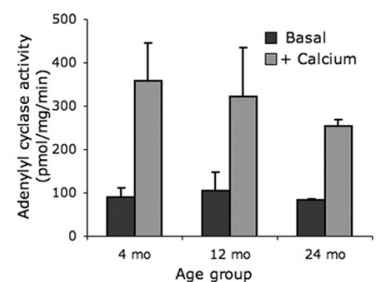

C Cerebellum

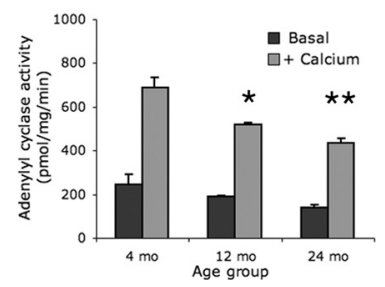

Figure 1. Brain $\mathrm{Ca}^{2+}$-stimulated adenylyl cyclase activity decreases with age. Brain adenylyl cyclase activity from wild-type mice was examined in tissue collected from mice at 4, 12, and 24 months of age. Dark gray bars represent baseline cyclase activity (Basal), and light gray bars represent cyclase activity in the presence of $5 \mu \mathrm{m}$ free $\mathrm{Ca}^{2+}$ ( + Calcium). In all brain regions and age groups, $\mathrm{Ca}^{2+}$ significantly stimulated adenylyl cyclase activity $(p<0.01$; two-way ANOVA with repeated measures across stimulation), as measured by picomoles of cAMP generated per milligram of protein per minute. $A, C^{2+}{ }^{2+}$ stimulated adenylyl cyclase activity in hippocampus. $\boldsymbol{B}, \mathrm{Ca}^{2+}$-stimulated adenylyl cyclase activity in cortex. $\boldsymbol{C}, \mathrm{Ca}^{2+}$-stimulated adenylyl cyclase activity in cerebellum. In all panels, ${ }^{*} p<0.05$ and ${ }^{* *} p<0.01$ (two-way ANOVA with repeated measures across stimulation; Bonferonni post test) compared with $\mathrm{Ca}^{2+}$-stimulated adenylyl cyclase activity at 4 months. In all groups, $n=2$ pooled tissue homogenates collected from three mice each.
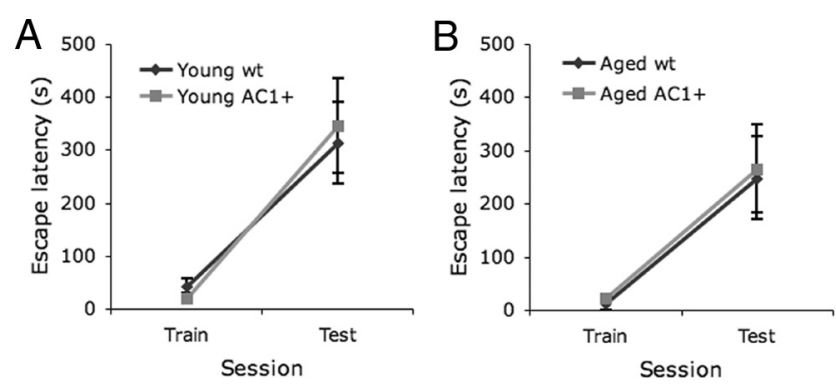

Figure 2. No detectable advantage of $\mathrm{AC}^{+}{ }^{+}$in passive avoidance fear memory tested $24 \mathrm{~h}$ after training. $\boldsymbol{A}$, Fear memory in the passive avoidance test was similar in aged $\mathrm{AC}^{+}$and wild-type (wt) littermates (wt, $n=9 ; \mathrm{AC}^{+}, n=13$ ). Both genotypes demonstrated increased escape latency after training (two-way ANOVA with repeated measures across session; $p<0.001)$. $B$, Fear memory in the passive avoidance test was similar in aged $\mathrm{AC}^{+}{ }^{+}$and wt littermates (wt, $n=9 ; \mathrm{AC}^{+}{ }^{+}, n=13$ ). Both groups demonstrated increased escape latency after training (two-way ANOVA with repeated measures across session; $p<0.001$ ).

deficits seen in mice lacking AC1 or AC8 only (Wong et al., 1999), indicating that these isoforms can compensate for the lack of the other.

To evaluate hippocampus-dependent fear memory, mice were trained for passive avoidance learning, a task reported to be impaired in advanced age (Mouravlev et al., 2006). We have previously demonstrated that long-term memory for passive avoidance requires $\mathrm{Ca}^{2+}$-stimulated adenylyl cyclases (Wong et al., 1999a). On the training day, mice were placed into a lit chamber and the latency to escape to a shaded side was measured. When mice entered the shaded side, they received a mild foot shock. Memory for the foot shock was demonstrated by the increased latency to enter the shaded side after reexposure to the lit chamber. In young mice (3-4 months) both $\mathrm{AC}^{+}$and wild-type littermates showed increased escape latency $24 \mathrm{~h}$ after training. No difference was observed between genotypes (Fig. 2A). Similarly, both aged (25-27 months old) $\mathrm{AC}^{+}$and wild-type littermates demonstrated increased escape latency $24 \mathrm{~h}$ after training, with no difference between genotype (Fig. $2 B$ ). These data suggest that $\mathrm{AC}^{+}$does not enhance passive avoidance memory in young or aged mice.

\section{Young but not aged $\mathrm{AC}^{+}{ }^{+}$mice have enhanced recognition memory}

Since young adult $\mathrm{ACl}^{+}$mice show enhanced recognition memory for novel objects (Wang et al., 2004), we hypothe- sized that the enhanced recognition memory would persist into old age. Unfortunately, when aged mice were trained with this protocol, the aged mice did not consistently explore objects during the training phase (see Materials and Methods). Therefore, aged mice were instead tested for social recognition memory, since mice are highly motivated to investigate other mice and long-term social memory has been shown to be hippocampusdependent (Kogan et al., 2000). During training, mice were repeatedly exposed to an individual female (familiar mouse). To test social recognition memory, mice were presented with the familiar mouse for 1 min, and then presented with a previously unexposed (novel) mouse. Young (3-4 months) mice spent more time investigating the novel mouse than the familiar mouse $24 \mathrm{~h}$ after training. This preference was not seen when the same mouse was presented twice (supplemental Fig. 1, available at www.jneurosci.org as supplemental material).

To determine whether social recognition memory requires $\mathrm{Ca}^{2+}$-stimulated adenylyl cyclases, we tested the DKO mice, mice lacking $\mathrm{AC} 1$ and $\mathrm{AC} 8$, for social recognition. For training, experimental mice aged 3-4 months were repeatedly exposed to the same ovariectomized female for six one-min sessions. Both wildtype and DKO mice significantly decreased investigation of the female over the training sessions (Fig. 3A), demonstrating that both genotypes recognized individual females. Three hours after training, a novel female was investigated more than the familiar female by both wild-type and DKO mice (Fig. 3B). Twenty-four hours after training, wild-type mice still demonstrated a preference for a novel over the familiar female, whereas DKO mice did not (Fig. 3C). These data demonstrate that longterm, but not short-term, recognition memory requires $\mathrm{Ca}^{2+}$ stimulated adenylyl cyclase.

We next compared young adult (3-4 months) $\mathrm{ACl}^{+}$mice and wild-type littermates for social recognition. Both wild-type and $\mathrm{ACl}^{+}$mice significantly decreased investigation of the female over the training sessions, with $\mathrm{ACl}^{+}$mice investigating the familiar female less than wild-type littermates over the training sessions $(p<0.05$; paired Student's $t$ test; Fig. $3 D)$. Although both genotypes recognized individual females, the difference in exploration could reflect faster learning by $\mathrm{AC} 1{ }^{+}$mice. This reduced exploration does not reflect less motivation to investigate mice since there was no difference between investigation by $\mathrm{ACl}^{+}$and wild-type mice when novel females were presented (Fig. $3 E, F)$. Both $\mathrm{ACl}^{+}$and wild-type mice spent more time investigating the novel mouse than the familiar mouse $24 \mathrm{~h}$ after training (Fig. 3E). Consistent with previous findings in the object recognition test (Wang et al., 2004), young $\mathrm{AC}^{+}$mice had a greater preference for novel over familiar mice than wild-type littermates $24 \mathrm{~h}$ after training, as measured by the ratio of exploration of the novel mouse compared with the familiar mouse $(p<0.05$; two-way ANOVA with subjects matched across genotype). Seven days after training young $\mathrm{ACl}^{+}$mice, but not young wild-type mice, still displayed a preference for the novel mouse (Fig. 3F). Consistent with data from the novel object recognition test (Wang et al., 2004), these data demonstrate that social recognition requires $\mathrm{Ca}^{2+}$-stimulated adenylyl cyclase and can be improved by AC1 overexpression. 
To determine whether $\mathrm{AC} 1$ overexpression benefits recognition memory during advanced age, aged $\mathrm{ACl}^{+}$and wild-type mice (25-27 months) were tested for social recognition. Both aged wild-type and $\mathrm{ACl}^{+}$mice significantly decreased investigation of the female over the training sessions (Fig. 4A), suggesting that both genotypes could recognize individual females. Although the average investigation times during training sessions were greater in $\mathrm{ACl}^{+}$mice than in wild-type littermates, this trend was not significant. Preference for the novel mouse was detected $3 \mathrm{~h}$ after training in both genotypes (Fig. 4B), suggesting that short-term social recognition memory was intact in both genotypes. However, when tested $24 \mathrm{~h}$ after training, no significant preference for the novel mouse was detected by either the aged $\mathrm{AC}^{+}$or wild-type littermates (Fig. 4C). These data suggest that memory for social recognition in aged mice is not improved by $\mathrm{AC} 1$ overexpression.

Although there was no difference between genotypes in social memory performance at 3 or $24 \mathrm{~h}$ after training, $\mathrm{ACl}^{+}$mice had increased overall investigation times compared with wild-type littermates $(p<0.05$; two-way ANOVA with subjects matched across genotype). To test whether this indicated a difference in mobility between genotypes, young and old mice were assayed for mobility by monitoring the time spent moving when exploring a novel chamber (supplemental Fig. 2, available at www.jneurosci.org as supplemental material). Young $\mathrm{AC}^{+}{ }^{+}$ and wild-type littermates exhibited similar movement times. Although both aged $\mathrm{ACl}^{+}$and wild-type aged littermates displayed significantly less mobility than young wild-type mice, the aged $\mathrm{ACl}^{+}$mice were more mobile than aged nontransgenic littermate mice. Thus, $\mathrm{AC} 1+$ mice retain more mobility into advanced age than wildtype littermate mice.

\section{Aged $\mathrm{ACl}^{+}$mice exhibit a defect in spatial memory}

Spatial memory was tested with the Barnes maze memory test (Fig. 5A). The Barnes maze is similar to the Morris water maze in that mice use visual cues to locate a goal, but mice walk on a platform as opposed to swimming. This was preferred for our study since aged mice can have difficulty swimming.

$\mathrm{Ca}^{2+}$-stimulated adenylyl cyclases are required for spatial memory in the Morris water maze (Wu et al., 1995). Although the Barnes maze was originally designed for rats, several Barnes maze protocols exist for testing mice. To verify that the requirement of $\mathrm{Ca}^{2+}$-stimulated adenylyl cyclases for spatial memory extended to the Barnes maze, we tested DKO mice. Accordingly, DKO mice exhibited impaired performance in the Barnes maze. During training, DKO mice showed a slower latency to find the goal

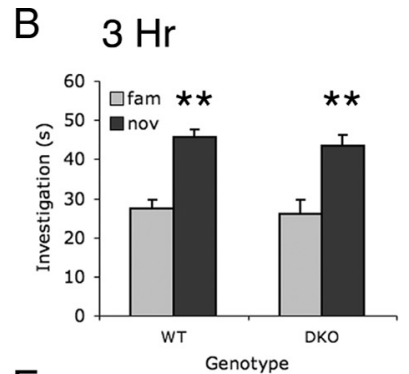

C $24 \mathrm{Hr}$

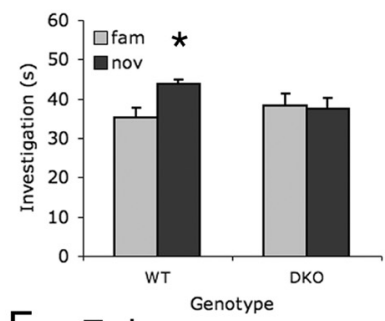

F 7 day
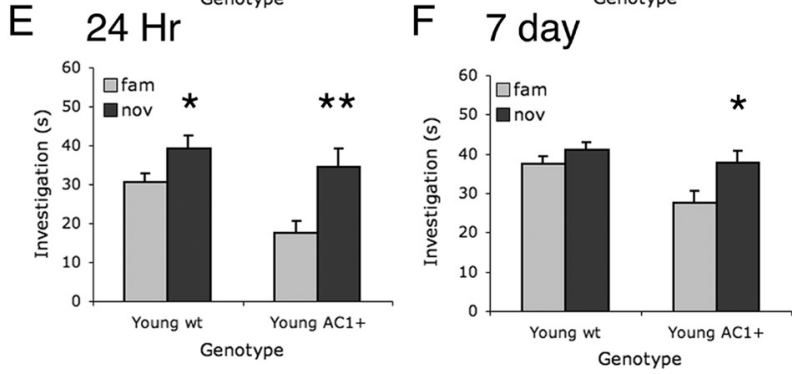

Figure 3. Social recognition memory in young DKO and $A C 1{ }^{+}$mice. $A$, Both DKO and wild-type (wt) mice significantly decrease investigation of the familiar female during training sessions ( $p<0.001$; two-way ANOVA with repeated measures across session) , Both wt and DKO mice show significantly increased investigation of novel (nov) over familiar (fam) mice $3 \mathrm{~h}$ after training , two-way ANOVA with repeated measures across exposure, Bonferroni post test). $C$, wt, but not DK0, mice show significantly increased investigation of novel over familiar mice $24 \mathrm{~h}$ after training ( ${ }^{*} p<0.01$; two-way ANOVA with repeated

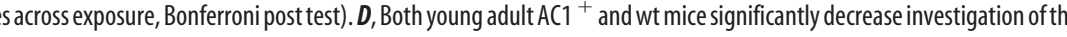
mice have a preference for novel over familiar mice $24 \mathrm{~h}$ after training ${ }^{*} p<0.05^{* *} p<0.01 \cdot$ two-way ANOVA with repeated nvestigation of the novel over the familiar female $\left({ }^{*} p<0.05\right.$; two-way ANOVA with subjects repeated measures across exposure,

A Train

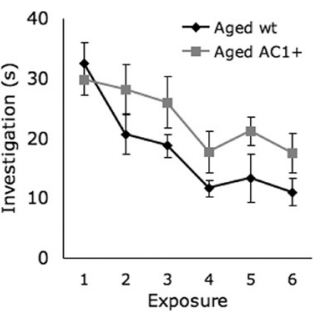

C $24 \mathrm{Hr}$

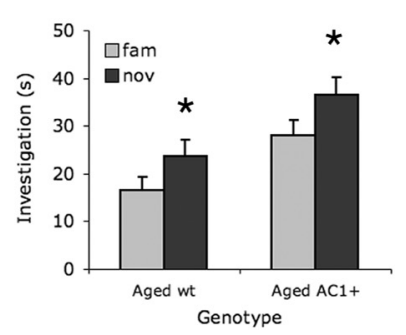

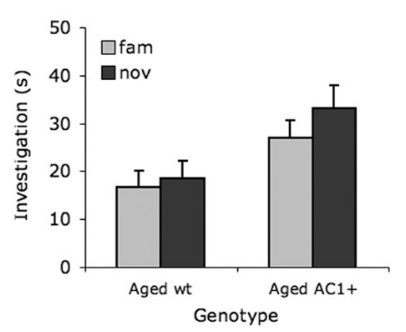

Figure 4. $\mathrm{ACl}^{+}$does not enhance social recognition memory in aged mice. $\boldsymbol{A}$, Both aged $\mathrm{AC}^{+}$and wild-type (wt) mice significantly decrease investigation of the familiar female during training sessions ( $p<0.01$; two-way ANOVA with repeated familiar (fam) mice $3 \mathrm{~h}$ after training ( ${ }^{*} p<0.05$; two-way ANOVA with repeated measures across exposure, Bonferroni post test). $\boldsymbol{C}$, Neither aged $\mathrm{AC}^{+}{ }^{+}$nor aged wt mice show significantly increased investigation of novel over familiar mice $24 \mathrm{~h}$ after training.

during the second session, but there was no difference between DKO and wild-type mice in subsequent sessions (Fig. 5B). During the probe trial, DKO mice spent less time and had fewer nose pokes in the target quadrant than wild-type mice (Fig. $5 C, D$ ). These data verify that $\mathrm{Ca}^{2+}$-stimulated adenylyl cyclases are required for spatial memory performance on the Barnes maze.

Although the young $\mathrm{ACl}^{+}$mice were shown to have enhanced recognition memory, spatial memory had not previously been tested with this strain. To test the effects of AC1 overexpression in spatial memory, young adult (3-4 months) $\mathrm{AC}^{+}$mice and wild-type littermates were tested on the Barnes maze. Young $\mathrm{AC}^{+}$and wild-type littermates exhibited no difference in escape latency during training (Fig. $5 E$ ), and there were no differences with time spent in the target quadrant (Fig. $5 F$ ) or nose pokes in the target quadrant (Fig. $5 G$ ) during the probe trial. No difference 
A

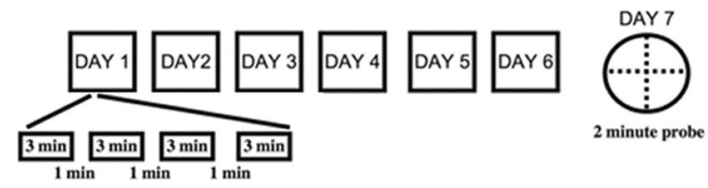

B
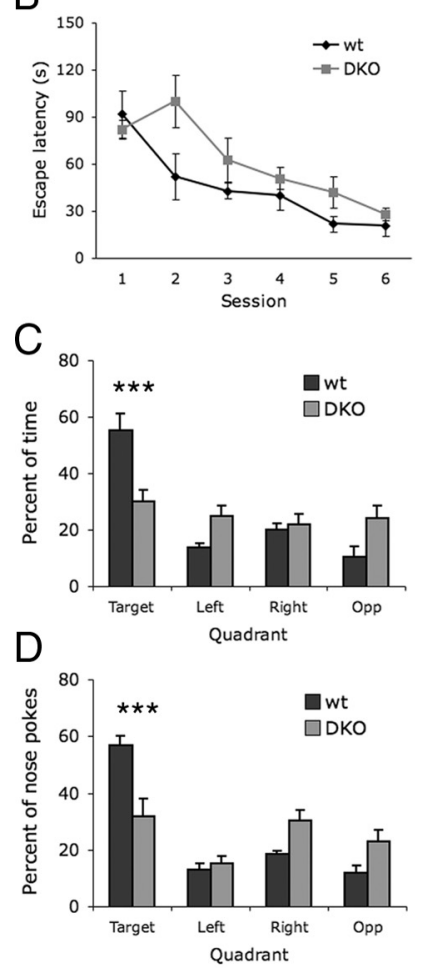

E
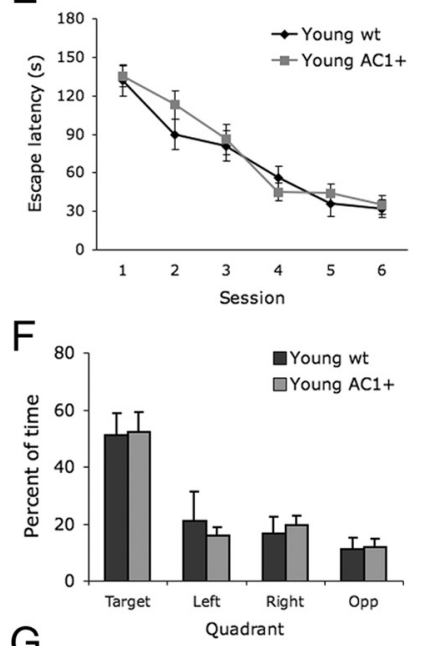

G

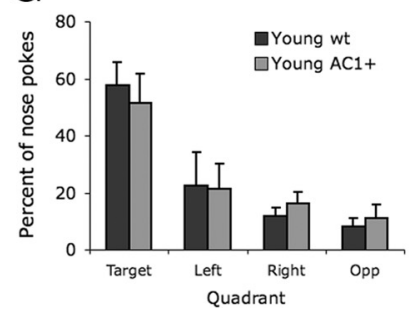

Figure 5. Spatial memory in young DKO and $\mathrm{AC}^{+}{ }^{+}$mice. $A$, Mice were trained over $6 \mathrm{~d}$, with daily training sessions of four trials spaced $1 \mathrm{~min}$ apart. Twenty-four hours after the last training session, mice were tested for a probe trial in the absence of the goal. $\boldsymbol{B}$, Escape latency between DKO and wild-type (wt) mice during Barnes maze training sessions. DKO mice had increased escape latency compared with wt mice on the second training session $\left({ }^{*} p<0.05\right.$; two-way ANOVA with repeated measures across session; Bonferroni post test). $C, \boldsymbol{D}$, Barnes maze probe test. DK0 mice spent less time $(\boldsymbol{C})$ and had fewer nose pokes $(\boldsymbol{D})$ in the target quadrant than did wild-type littermates $\left({ }^{* * *} p<0.001\right.$; two-way ANOVA with repeated measures across quadrant; Bonferroni post test). DKO, $n=8 ; \mathrm{wt}, n=8 . E$, Escape latency during training sessions in young $\mathrm{AC}^{+}$and wild-type littermates. $\boldsymbol{F}, \boldsymbol{G}$, Performance of young $\mathrm{AC1}^{+}$and young wt littermates on the probe test was similar with respect to time spent $(\boldsymbol{F})$ and nose pokes $(\boldsymbol{G})$ in the target quadrant. Young $\mathrm{AC}^{+}{ }^{+}, n=14$; young wt, $n=9$.

was detected between $\mathrm{ACl}^{+}$and wild-type littermates when the probe test was administered after only 4 training sessions to a separate set of mice; this ruled out differences between genotypes in the rate of spatial memory acquisition (data not shown). These data suggest that there is no detectable benefit or detriment of $\mathrm{ACl}$ overexpression in spatial memory of young adult mice.

To examine the effects of $\mathrm{ACl}$ overexpression on spatial memory in aged mice, we tested aged (25-27 months) $\mathrm{AC} 1^{+}$mice and wild-type littermates with the Barnes maze. During the training sessions, aged $\mathrm{AC}^{+}$and wild-type littermates had similar escape latencies (Fig. 6A). Both aged $\mathrm{ACl}^{+}$and their nontransgenic littermates showed progressively shorter escape latencies as training sessions progressed, indicating that both groups were equally motivated to escape into the goal tunnel. During the probe test, however, aged $\mathrm{ACl}^{+}$mice spent less time exploring the target quadrant (Fig. $6 \mathrm{~B}$ ) and a smaller fraction of their nose pokes occurred in the target quadrant than wild-type littermates (Fig. $6 C$ ). The impaired performance on the probe test is not likely because of the mobility of the aged $\mathrm{AC}^{+}$mice (supplemental
Fig. 2, available at www.jneurosci.org as supplemental material), since mice that are more active (young $\mathrm{ACl}+$ and wild-type) and mice that are less active (aged wild-type) than the aged $\mathrm{AC1}^{+}$ mice both show greater preference for the target quadrant than the aged $\mathrm{AC}^{+}$mice (Figs. 5, 6). These data indicate that AC1 overexpression impairs spatial memory in aged mice.

Aged rats have well documented impairments in Barnes maze performance, and aged mice exhibit spatial memory deficits in the Morris water maze (D'Hooge and De Deyn, 2001; Rosenzweig and Barnes, 2003). Thus, the robust preference for the target quadrant in the probe test by aged wild-type mice (Fig. $6 B, C$ ) was unexpected. To test whether aged wild-type mice have impaired spatial memory performance on the Barnes maze, we directly compared young (3-4 month) and aged (25-26 month) mice to assess the effect of age on performance (supplemental Fig. 3, available at www.jneurosci.org as supplemental material). Aged mice had slower escape latencies than young mice during training sessions ( $p<0.05$; supplemental Fig. $3 A$, available at www. jneurosci.org as supplemental material). However, no difference was detected in time spent (supplemental Fig. 3B, available at www.jneurosci.org as supplemental material) or percentage of nose pokes (supplemental Fig. 3C, available at www.jneurosci.org as supplemental material) in the target quadrant during the probe test. Although aged mice show slower mobility, these data could reflect in part a slower spatial learning by aged mice. In support of this, we have observed that 3-month-old mice form a preference for the target quadrant in the probe test after only 4 training sessions, whereas mice aged to 21 months do not (data not shown). Regardless, the unexpected performance of aged wild-type mice on the Barnes maze may have unmasked a deficit in $\mathrm{ACl}^{+}$mice that would have been missed under conditions in which wild-type spatial memory was weaker.

\section{Aged $\mathrm{ACl}^{+}$mice have enhanced adenylyl cyclase activity}

To verify that aged $\mathrm{ACl}^{+}$mice retained increased adenylyl cyclase activity in advanced age, hippocampal membrane fractions were obtained from young (4 months) and aged (26 months) $\mathrm{ACl}^{+}$and wild-type littermates. Membrane fractions were assayed for adenylyl cyclase activity in the absence or presence of 5 $\mu \mathrm{M}$ free $\mathrm{Ca}^{2+}$. Consistent with previous reports (Wang et al., 2004), young $\mathrm{ACl}^{+}$mice had significantly greater $\mathrm{Ca}^{2+}$. stimulated adenylyl cyclase activity than young wild-type littermates (Fig. 7A). In both young $\mathrm{AC}^{+}$and littermate controls, $\mathrm{Ca}^{2+}$ increased adenylyl cyclase activity (both groups, $p<0.01$, two-way ANOVA with repeated measures across treatment). The aged $\mathrm{ACl}^{+}$mice also had significantly greater hippocampal adenylyl cyclase activity than aged wild-type littermates (Fig. $7 B$ ). As with the young tissue, $\mathrm{Ca}^{2+}$ increased the adenylyl cyclase activity in both aged $\mathrm{ACl}^{+}$and wild-type hippocampi $(p<0.01$, two-way ANOVA with repeated measures across treatment). Confirming our earlier observation (Fig. $1 A$ ), aged $\mathrm{ACl}^{+}$and wild-type littermates had significantly lower hippocampal $\mathrm{Ca}^{2+}$ stimulated adenylyl cyclase activity than younger mice of the same genotype ( $p<0.01$, two-way ANOVA with repeated measures across treatment; Bonferroni post test) (Figs. 7 $A, B$ ). These data suggest that although both genotypes experience decreased $\mathrm{Ca}^{2+}$-stimulated adenylyl cyclase activity resulting from aging, aged $\mathrm{ACl}^{+}$mice retain enhanced $\mathrm{Ca}^{2+}$-stimulated adenylyl cyclase activity over age-matched controls.

Young $\mathrm{ACl}^{+}$mice have elevated levels of hippocampal cAMP and phospho-CREB (Wang et al., 2004). Hippocampal tissue from aged $\mathrm{AC}^{+}{ }^{+}$and wild-type littermates were isolated to determine whether the elevated levels of cAMP/CREB sig- 
naling persist into advanced age. Consistent with previous findings in young $\mathrm{ACl}^{+}$ mice (Wang et al., 2004), ELISA analysis showed greater levels of cAMP in the aged (26 months) $\mathrm{ACl}^{+}$hippocampus compared with aged wild-type littermates. Aged wild-type hippocampus contained ( \pm SEM) $32.9 \pm 3.8 \mathrm{ng}$ of $\mathrm{cAMP} / \mathrm{mg}$ of total protein, whereas aged $\mathrm{ACl}^{+}$hippocampus contained $45.4 \pm 4.6 \mathrm{ng}$ of $\mathrm{cAMP} / \mathrm{mg}$ of total protein. This difference was statistically significant ( $p<0.05$, unpaired Student's t test, both groups: $n=6)$. Additionally, aged $\mathrm{ACl}^{+}$hippocampus exhibited elevated levels of phospho-CREB (supplemental Fig. $4 A$, available at www.jneurosci.org as supplemental material). Western blot analysis of CREB phosphorylated at ser 133 normalized to total actin levels was performed in hippocampal lysates of wild-type littermate and $\mathrm{ACl}^{+}$mice. Values were reported as a ratio of the value in aged wild-type littermates. Wild-type hippocampus contained $( \pm$ SEM) $1.00 \pm 0.07$ normalized phospho-CREB signal, whereas aged $\mathrm{AC}^{+}$hippocampus contained $1.59 \pm 0.19$ normalized phospho-CREB signal. This difference was statistically significant $(p<0.05$, unpaired Student's $t$ test, both groups: $n=4)$.

\section{Neural and glial markers are unchanged in aged $\mathrm{ACl}^{+}$mice}

To rule out widespread neurotoxic effects of the $\mathrm{AC} 1^{+}$genotype on the aged hippocampus, we performed Western analysis for neuronal and glial markers in aged hippocampal tissue. No difference was observed in hippocampal weights harvested from aged mice between $\mathrm{ACl}^{+}$and nontransgenic mice. No changes were seen in levels of $\beta$ III tubulin (supplemental Fig. $4 B$, available at www.jneurosci.org as supplemental material) or GFAP (supplemental Fig. 4C, available at www.jneurosci.org as supplemental material) normalized to actin levels between $\mathrm{AC}^{+}$and wild-type littermates. Although subtle differences may exist between aged $\mathrm{ACl}^{+}$and their wild-type littermates, these data rule out severe neurotoxicity caused by $\mathrm{AC} 1$ overexpression as an explanation for impaired spatial memory in aged $\mathrm{ACl}^{+}$mice.

\section{Discussion}

We hypothesized that progressive loss of $\mathrm{Ca}^{2+}$-stimulated adenylyl cyclases contribute to memory deficits associated with aging and that overexpression of AC1 might improve the memory of older mice. We demonstrate that $\mathrm{Ca}^{2+}$-stimulated adenylyl cyclase activity decreased in hippocampi of mice aged 12 and 24 months. We also demonstrated that the enhanced recognition memory of AC1 overexpression extended to social recognition memory in young adults. However, older $\mathrm{AC}^{+}{ }^{+}$mice showed no benefit in fear or recognition memory. Surprisingly, aged $\mathrm{ACl}^{+}$mice exhibited poorer spatial memory than agematched wild-type littermates. This impairment was agedependent. Biochemical analysis indicated that both $\mathrm{AC}^{+}$and nontransgenic littermates had attenuated $\mathrm{Ca}^{2+}$-stimulated adenylyl cyclase activity during aging, but that aged $\mathrm{AC}^{+}$mice retained enhanced adenylyl cyclase activity relative to wild-type mice. Aged $\mathrm{ACl}^{+}$mice had greater levels of hippocampal cAMP and phospho-CREB, indicating that there was likely no agerelated signaling compensation downstream of adenylyl cyclase in the $\mathrm{ACl}^{+}$mouse.

To our knowledge, this is the first example of a transgenic mouse whose mutation is beneficial to memory at a young age but detrimental in old age. This phenomenon, however, is task
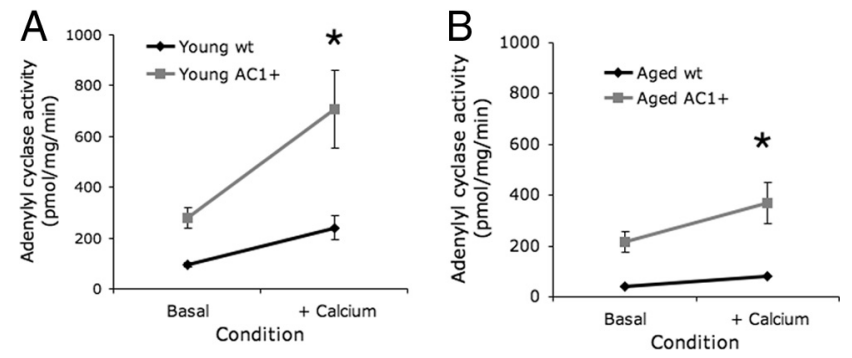

Figure 7. Aged $\mathrm{AC}^{+}$mice have enhanced adenylyl cyclase activity and cAMP signaling. $A$, $B$, Membrane fractions from hippocampus were measured for adenylyl cyclase activity as picomoles of CAMP generated per milligram of sample protein per minute. $A$, Adenylyl cyclase activity of young $\mathrm{AC}^{+}$and wild-type (wt) littermates in the absence or presence of $5 \mu \mathrm{m}$ free $\mathrm{Ca}^{2+}$. B, Adenylyl cyclase activity of aged $\mathrm{AC}^{+}{ }^{+}$and wild-type littermates in the absence or presence of $5 \mu \mathrm{m}$ free $\mathrm{Ca}^{2+}$. In both young and aged groups, $n=4$ pools of tissue homogenate collected from three mice each. ${ }^{*} p<0.05$ between genotypes (two-way ANOVA with repeated measures across stimulation; Bonferonni post test).

specific. AC1 overexpression benefits recognition memory in young adult mice, but this benefit does not extend to old age. Furthermore, the benefits of AC1 overexpression did not extend to performance in the passive avoidance or the Barnes maze tests in young mice. Conversely, AC1 overexpression impaired spatial memory of aged mice in the Barnes maze, whereas fear and social recognition memory remained intact. The failure of AC1 overexpression to improve performance on the tests we administered may indicate that reduction of $\mathrm{Ca}^{2+}$-stimulated adenylyl cyclase activity in the aged hippocampus is optimized for the aged brain.

Here we report that $\mathrm{Ca}^{2+}$-stimulated adenylyl cyclase activity is decreased in the aged hippocampus. The advantage of the adenylyl cyclase assay is that it measures the activity of adenylyl cyclase under experimenter-defined conditions. Thus, it can detect changes in functionality that might not be reflected by total mRNA or protein levels present in the tissue. Although the assay does not specify how much the reduced $\mathrm{Ca}^{2+}$-stimulated activity seen in aged animals (Figs. 1, 7B) is the result of changes in $\mathrm{AC} 1$ versus AC8 activity, it does demonstrate that the overall cAMP production in response to $\mathrm{Ca}^{2+}$ is reduced in the aged hippocampus.

These behavioral tests were chosen for this study because they all require $\mathrm{Ca}^{2+}$-stimulated adenylyl cyclases to some degree and are hippocampus-dependent, yet test different types of memory. The different effects of AC1 overexpression on these tasks could reflect different degrees of difficulty of each task. Aged wild-type mice did not demonstrate long-term memory for social recognition, so a possible memory deficit in aged $\mathrm{AC}^{+}$mice would be undetectable. Since aged wild-type mice could acquire spatial 
memory in the Barnes maze task, it was possible to observe a spatial memory deficit in aged $\mathrm{ACl}^{+}$mice.

Alternatively, the different outcomes for each test could be caused by different integration of brain regions outside the hippocampus for each memory task, which may have different sensitivities to the transgene. For example, while increasing cAMP levels has been reported to improve hippocampus-dependent memory in aged rodents, it impairs prefrontal cortex-dependent working memory performance in young and aged rats (Taylor et al., 1999; Ramos et al., 2003). Although spatial memory performance remains intact after lesions of prefrontal cortex in rodents (de Bruin et al., 1994; Granon and Poucet, 1995; Lacroix et al., 2002), these data do suggest that increasing cAMP can have different effects on processing by different brain regions. In this regard, aged hippocampus and cerebellum had significantly decreased $\mathrm{Ca}^{2+}$-stimulated adenylyl cyclase activity, whereas aged cortex did not. Overexpression of AC1 under the CaMKII promoter drives expression across the forebrain, including areas which may not have significantly reduced $\mathrm{Ca}^{2+}$-stimulated adenylyl cyclase activity in advanced age. Interestingly, there are numerous examples of transgenic mice that show different effects on different hippocampus dependent tasks (for review, see Mizuno, 2005).

The effects on memory seen in $\mathrm{ACl}^{+}$mice resemble a phenomenon in evolutionary biology known as antagonistic pleiotropy, whereby a gene product benefits reproductive fitness in the young organism but harms the organism later in life (Rose, 1991; Martin, 2007; Pietá Dias et al., 2007). In the case of $\mathrm{ACl}^{+}$mice, the increased AC1 activity benefits recognition memory in the young adult but impairs spatial memory in advanced age. This suggests that the optimal level of hippocampal AC1 enzymatic activity for spatial memory shifts to lower levels during aging. Thus, lower levels of $\mathrm{Ca}^{2+}$-stimulated adenylyl cyclase activity in the aged brain (Fig. 1) might reflect a mechanism to optimize $\mathrm{Ca}^{2+}$-stimulated adenylyl cyclase signaling for memory function in aged mice.

Although we report no difference between young and aged wild-type mice on the probe test after 6 training sessions (supplemental Fig. 3, available at www.jneurosci.org as supplemental material), the increased escape latency of aged mice during training could be due in part to slower acquisition of spatial memory by aged mice. Strong performance on the Barnes maze probe was surprising, given reports of spatial memory deficits of aged mice with probe tests on the Morris water maze (D'Hooge and De Deyn, 2001), and that memory deficits with the DKO mice were detectable with our Barnes maze protocol. However, the Morris water maze might be more difficult for mice than the Barnes maze since the water maze causes more stress to mice (Harrison et al., 2009). Aged mice show slower acquisition of spatial memory on the Morris water maze, even when swimming mobility is taken into account (Murphy et al., 2006). Thus, the strong preference for the target quadrant seen in aged mice could be attributable to the amount of training the mice receive in our Barnes maze protocol; multiple sessions could allow the performance of aged mice to catch up to the young mice. In support of this, we have observed that young mice trained for only four sessions form a significant preference for the target quadrant in the probe test for the Barnes maze whereas 21-month-old mice do not (data not shown). Regardless, the strong performance in aged mice allowed for the observation of the impaired spatial memory in age-matched $\mathrm{AC}^{+}$mice, which could have been missed under conditions in which aged wild-type memory was weaker.
Why would overexpression of AC1 impair spatial memory in aged mice? One possibility is that $\mathrm{ACl}$ is stimulated by $\mathrm{Ca}^{2+}$ / calmodulin and the dynamics of $\mathrm{Ca}^{2+}$ signaling in neurons change with age (Thibault et al., 2007; Toescu and Verkhratsky, 2007). $\mathrm{Ca}^{2+}$ influx through L-type voltage-gated calcium channels (VGCCs) in the hippocampus increases with age (Campbell et al., 1996; Thibault and Landfield, 1996), and clearance of internal $\mathrm{Ca}^{2+}$ is slowed by aging (Toescu and Verkhratsky, 2007). Thus, signaling events in aged neurons can result in altered duration and amplitude of internal free $\mathrm{Ca}^{2+}$ levels. Age-related deficits in animal models of memory have been ameliorated by nimodipine, an L-type VGCC antagonist (Deyo et al., 1989; Straube et al., 1990; Veng et al., 2003) or memantine, an NMDA receptor antagonist (Pietá Dias et al., 2007; Burke et al., 2008). These data suggest that memory processing in the aged brain suffers from disregulated $\mathrm{Ca}^{2+}$ signaling. The $\mathrm{AC} 1{ }^{+}$mutant may be detrimental to memory specifically in aged animals specifically because $\mathrm{AC} 1$ is stimulated by $\mathrm{Ca}^{2+}$ signaling.

In this regard, it is noteworthy that not all genetic manipulations that enhance cAMP production improve hippocampusdependent memory in mice. For example, the $\mathrm{G}_{\mathrm{i}} \alpha$ knock-out mouse has enhanced hippocampal late phase LTP but impaired hippocampus-dependent fear, recognition, and spatial memories (Pineda et al., 2004). Furthermore, hippocampus-dependent memory is impaired when $G_{i}$ is inhibited in the specifically hippocampus either pharmacologically or with antisense DNA oligonucleotides (Pineda et al., 2004). This demonstrates that memory processing by the hippocampus can be disrupted by elevated CAMP levels, possibly reflecting a saturation of cAMP signaling that complicates memory processing. The $\mathrm{AC}{ }^{+}$mouse may reflect that the threshold for improved memory by increased cAMP is lower in aged mice than in young mice.

In summary, we report that $\mathrm{Ca}^{2+}$-stimulated adenylyl cyclase activity decreases in the aged hippocampus. Increasing the expression of $\mathrm{ACl}$ enhanced recognition memory in young mice, but fails to improve fear or recognition memory in aged mice. Furthermore, AC1 overexpression in aged mice impairs spatial memory. These results were surprising, particularly since aged $\mathrm{AC}^{+}{ }^{+}$showed $\mathrm{Ca}^{2+}$-stimulated adenylyl cyclase activity similar to that of young adult wild-type mice. The downregulation of hippocampal $\mathrm{Ca}^{2+}$-stimulated adenylyl cyclase activity during aging may be a mechanism to insure that increased $\mathrm{Ca}^{2+}$ in older neurons does not lead to cAMP levels that are detrimental to memory formation.

\section{References}

Bach ME, Barad M, Son H, Zhuo M, Lu YF, Shih R, Mansuy I, Hawkins RD, Kandel ER (1999) Age-related defects in spatial memory are correlated with defects in the late phase of hippocampal long-term potentiation in vitro and are attenuated by drugs that enhance the cAMP signaling pathway. Proc Natl Acad Sci U S A 96:5280-5285.

Barad M, Bourtchouladze R, Winder DG, Golan H, Kandel E (1998) Rolipram, a type IV-specific phosphodiesterase inhibitor, facilitates the establishment of long-lasting long-term potentiation and improves memory. Proc Natl Acad Sci U S A 95:15020-15025.

Burke SN, Maurer AP, Yang Z, Navratilova Z, Barnes CA (2008) Glutamate receptor-mediated restoration of experience-dependent place field expansion plasticity in aged rats. Behav Neurosci 122:535-548.

Campbell LW, Hao SY, Thibault O, Blalock EM, Landfield PW (1996) Aging changes in voltage-gated calcium currents in hippocampal CA1 neurons. J Neurosci 16:6286-6295.

Conti AC, Maas JW Jr, Muglia LM, Dave BA, Vogt SK, Tran TT, Rayhel EJ, Muglia LJ (2007) Distinct regional and subcellular localization of adenylyl cyclases type 1 and 8 in mouse brain. Neuroscience 146:713-729.

Dai H, Kaneko K, Kato H, Fujii S, Jing Y, Xu A, Sakurai E, Kato M, Okamura 
N, Kuramasu A, Yanai K (2007) Selective cognitive dysfunction in mice lacking histamine $\mathrm{H} 1$ and $\mathrm{H} 2$ receptors. Neurosci Res 57:306-313.

de Bruin JP, Sànchez-Santed F, Heinsbroek RP, Donker A, Postmes P (1994) A behavioural analysis of rats with damage to the medial prefrontal cortex using the Morris water maze: evidence for behavioural flexibility, but not for impaired spatial navigation. Brain Res 652:323-333.

Deyo RA, Straube KT, Disterhoft JF (1989) Nimodipine facilitates associative learning in aging rabbits. Science 243:809-811.

D’Hooge R, De Deyn PP (2001) Applications of the Morris water maze in the study of learning and memory. Brain Res Brain Res Rev 36:60-90.

Eckel-Mahan KL, Phan T, Han S, Wang H, Chan GC, Scheiner ZS, Storm DR (2008) Circadian oscillation of hippocampal MAPK activity and cAMP: implications for memory persistence. Nat Neurosci 11:1074-1082.

Granon S, Poucet B (1995) Medial prefrontal lesions in the rat and spatial navigation: evidence for impaired planning. Behav Neurosci 109:474-484.

Harrison FE, Hosseini AH, McDonald MP (2009) Endogenous anxiety and stress responses in water maze and Barnes maze spatial memory tasks. Behav Brain Res 198:247-251.

Kelly KM, Nadon NL, Morrison JH, Thibault O, Barnes CA, Blalock EM (2006) The neurobiology of aging. Epilepsy Res 68 [Suppl 1]:S5-S20.

Kogan JH, Frankland PW, Silva AJ (2000) Long-term memory underlying hippocampus-dependent social recognition in mice. Hippocampus 10:47-56.

Lacroix L, White I, Feldon J (2002) Effect of excitotoxic lesions of rat medial prefrontal cortex on spatial memory. Behav Brain Res 133:69-81.

Martin G (2007) Modalities of gene action predicted by the classical evolutionary biological theory of aging. Ann N Y Acad Sci 1100:14-20.

Mizuno K, Giese KP (2005) Hippocampus-dependent memory formation: do memory type-specific mechanisms exist? J Pharmacol Sci 98:191-197.

Mouravlev A, Dunning J, Young D, During MJ (2006) Somatic gene transfer of cAMP response element-binding protein attenuates memory impairment in aging rats. Proc Natl Acad Sci U S A 103:4705-4710.

Murphy GG, Rahnama NP, Silva AJ (2006) Investigation of age-related cognitive decline using mice as a model system: behavioral correlates. Am J Geriatr Psychiatry 14:1004-1011.

Pietá Dias C, Martins de Lima MN, Presti-Torres J, Dornelles A, Garcia VA, Siciliani Scalco F, Rewsaat Guimarães M, Constantino L, Budni P, DalPizzol F, Schröder N (2007) Memantine reduces oxidative damage and enhances long-term recognition memory in aged rats. Neuroscience 146:1719-1725.

Pineda VV, Athos JI, Wang H, Celver J, Ippolito D, Boulay G, Birnbaumer L, Storm DR (2004) Removal of G(ialphal) constraints on adenylyl cyclase in the hippocampus enhances LTP and impairs memory formation. Neuron 41:153-163.

Ramos BP, Birnbaum SG, Lindenmayer I, Newton SS, Duman RS, Arnsten AF (2003) Dysregulation of protein kinase a signaling in the aged prefrontal cortex: new strategy for treating age-related cognitive decline. Neuron 40:835-845.

Rose MR (1991) Evolutionary biology of aging. New York: Oxford UP.
Rosenzweig ES, Barnes CA (2003) Impact of aging on hippocampal function: plasticity, network dynamics, and cognition. Prog Neurobiol 69:143-179.

Shan Q, Chan GC, Storm DR (2008) Type 1 adenylyl cyclase is essential for maintenance of remote contextual fear memory. J Neurosci 28: $12864-12867$.

Sindreu CB, Scheiner ZS, Storm DR (2007) Ca2+-stimulated adenylyl cyclases regulate ERK-dependent activation of MSK1 during fear conditioning. Neuron 53:79-89.

Straube KT, Deyo RA, Moyer JR Jr, Disterhoft JF (1990) Dietary nimodipine improves associative learning in aging rabbits. Neurobiol Aging 11:659-661.

Taylor JR, Birnbaum S, Ubriani R, Arnsten AF (1999) Activation of cAMPdependent protein kinase $\mathrm{A}$ in prefrontal cortex impairs working memory performance. J Neurosci 19:RC23:1-5.

Thibault O, Landfield PW (1996) Increase in single L-type calcium channels in hippocampal neurons during aging. Science 272:1017-1020.

Thibault O, Gant JC, Landfield PW (2007) Expansion of the calcium hypothesis of brain aging and Alzheimer's disease: minding the store. Aging Cell 6:307-317.

Toescu EC (2005) Normal brain ageing: models and mechanisms. Philos Trans R Soc Lond B Biol Sci 360:2347-2354.

Toescu EC, Verkhratsky A (2007) The importance of being subtle: small changes in calcium homeostasis control cognitive decline in normal aging. Aging Cell 6:267-273.

Tombaugh GC, Rowe WB, Rose GM (2005) The slow afterhyperpolarization in hippocampal CA1 neurons covaries with spatial learning ability in aged Fisher 344 rats. J Neurosci 25:2609-2616.

Veng LM, Mesches MH, Browning MD (2003) Age-related working memory impairment is correlated with increases in the L-type calcium channel protein alpha1D (Cav1.3) in area CAl of the hippocampus and both are ameliorated by chronic nimodipine treatment. Brain Res Mol Brain Res 110:193-202.

Villacres EC, Wu Z, Hua W, Nielsen MD, Watters JJ, Yan C, Beavo J, Storm DR (1995) Developmentally expressed $\mathrm{Ca}(2+)$-sensitive adenylyl cyclase activity is disrupted in the brains of type I adenylyl cyclase mutant mice. J Biol Chem 270:14352-14357.

Wang H, Ferguson GD, Pineda VV, Cundiff PE, Storm DR (2004) Overexpression of type- 1 adenylyl cyclase in mouse forebrain enhances recognition memory and LTP. Nat Neurosci 7:635-642.

Wong ST, Athos J, Figueroa XA, Pineda VV, Schaefer ML, Chavkin CC, Muglia LJ, Storm DR (1999) Calcium-stimulated adenylyl cyclase activity is critical for hippocampus-dependent long-term memory and late phase LTP. Neuron 23:787-798.

Wu ZL, Thomas SA, Villacres EC, Xia Z, Simmons ML, Chavkin C, Palmiter RD, Storm DR (1995) Altered behavior and long-term potentiation in type I adenylyl cyclase mutant mice. Proc Natl Acad Sci U S A 92:220-224.

Xia Z, Choi EJ, Wang F, Blazynski C, Storm DR (1993) Type I calmodulinsensitive adenylyl cyclase is neural specific. J Neurochem 60:305-311. 